\title{
Identidades e relações de gênero nos guias do programa nacional dos livros didáticos de História e Português para o ensino médio
}

\author{
Identities and gender relations in national textbook program \\ guides for History and Portuguese at high school level
}

\author{
Luís César Castrillon MENDES'1 \\ Dánie Marcelo de JESUS²
}

\begin{abstract}
Resumo
Neste artigo, analisamos a presença da discussão de gênero nas avaliaçóes expressas nos Guias do PNLD 2015. Teoricamente, utilizou-se o conceito de gênero como categoria de análise, associado a alguns aspectos dos estudos decoloniais com a finalidade de entender o modo como o conceito de identidade se apresentava nos guias. Em complemento, analisou-se também se esses documentos se voltam para especificidades de grupos, tais como classe social, etnia e sexualidade. Conclui-se que os guias, de modo geral, parecem reforçar o não protagonismo feminino e o total silenciamento de questóes relacionadas com as outras manifestaçóes de gênero não canônicas.
\end{abstract}

Palavras-chave: Identidade/Relaçóes de Gênero. Guias do PNLD. Ensino Médio.
Abstract

This paper addresses the gender debate in assessments presented in teacher guides by the PNLD 2015. For the theoretical framework, the concept of gender was used as an analytical category, together with some aspects of postcolonial and decolonial studies to understand how the concept of identity was introduced in the guides. In addition, this paper analyzes whether these guides address group specificities like social class, ethnicity, and sexuality. Results suggest that guides generally seem to reinforce women's secondary role and a complete silencing of issues related to other non-canonical gender expressions.

Keywords: Identity/Gender Relations. PNLD Guides. High School.

1 Doutor em História, membro do grupo de pesquisa História, Gênero e Interculturalidade, Professor Adjunto da Universidade Federal da Grande Dourados - UFGD, Rodovia Dourados - Itahum, Km 12 - Cidade Universitária, Dourados/MS. CEP: 79.804-970, Tel.: (067) 3410-2286 - Ramal 2286. Email: <luismendes@ufgd.edu.br>

2 Doutor em Linguística Aplicada, coordenador do Grupo de pesquisa Linguagem, letramentos e diferenças. Professor Associado da Universidade Federal de Mato Grosso, UFMT. Av. Fernando Corrêa da Costa, n ${ }^{\circ}$ 2367-Cuiabá/ MT. CEP: 78060-900. Email: <daniepuc@gmail.com>.

R. Educ. Públ.

Cuiabá

v. 27

n. $65 / 2$

p. $693-712$ maio/ago. 2018 


\section{Introdução}

A utilização dos livros didáticos no cotidiano escolar se revela prática frequente em sala de aula. Assim como os currículos, eles representam aquilo que foi selecionado culturalmente para se transmitir às futuras geraçóes. Alvo de críticas e polêmicas de diversas naturezas, seja pelo seu apagamento das diferenças sociais, seja pelo engessamento de práticas educacionais, seja ainda pela fixação de verdades absolutas. O livro didático, contudo, é espaço/território de poder, na medida em que reflete os interesses dos grupos que o fabricam.

Produções nas últimas décadas (BEZERRA; LUCA, 2006; BITTENCOURT, 2008; MARTINS, 2011), especialmente em relação aos livros didáticos, têm se voltado para o estudo das representaçóes da cultura, da literatura e da história dos grupos sociais silenciados e estigmatizados pela chamada narrativa tradicional. É o caso do protagonismo feminino nos textos histórico-literários. Tais discriminaçóes, preconceitos e estereótipos continuam sendo (re)produzidos pelo discurso escolar. A leitura que ainda se privilegia é centrada nos textos canonizados pelos centros considerados de excelência, em detrimento daqueles que trazem as singularidades de outros eixos de produção. Como afirma Bosi (2010), a periferia move-se, portanto não há como desconsiderar o mundo plural e todas suas nuances, aproximando-se cada vez mais do leitor comum para quem o acesso ao mundo da literatura ainda é restrito.

Diante desse quadro, o objetivo deste artigo é analisar a presença da discussão de gênero nas avaliaçóes expressas nos Guias endereçados aos professores de História e de Português do ensino médio do Programa Nacional do Livro Didático (PNLD) de 2015. Como critério metodológico a escolha das obras se deu por aquelas adotadas no Estado de Mato Grosso, o contexto de nossa atuação profissional.

Para essa operação analítica literário-historiográfica ${ }^{3}$, partimos de uma identidade concebida de forma histórica, contingente e relacional. O livro didático, dessa forma, levando em consideração as análises de Silva (2013, p. 97) sobre currículo, constitui, dentre outras possibilidades, "[...] um artefato de gênero, na medida em que corporifica e (re)produz essas relaçóes".

O percurso escolhido para fundamentar nossa posiçáo inclui, de princípio,

3 Michel de Certeau (1925-1986) foi um intelectual francês que produziu trabalhos em diversos campos do conhecimento, tais como, História, Sociologia, Antropologia, Filosofia e Psicanálise. Para esse autor, se faz uma operação historiográfica com a combinação de um lugar social, práticas científicas e uma escrita. Em razão desse lugar em que se instauram os métodos que delineiam uma topografia de interesses que os documentos e as questôes, que lhes serão propostas, se organizam (CERTEAU, 2002). 
uma discussão em torno da relação livro didático e gêneros. Logo em seguida, nos apropriamos dos estudos decoloniais com finalidade de demarcar nosso lócus de enunciação e tom analítico de nosso trabalho. A seguir, procuramos alinhavar nosso referencial teórico com a análise dos guias para os professores. Ao final, expomos reflexóes preliminares dessa questão.

\section{Relações de gênero e livro didático}

Com relação a determinados grupos invisibilizados nas narrativas dos livros didáticos, neste estudo, em particular as mulheres, normalmente eram associadas ao mundo considerado privado, em oposição aos homens pertencentes à esfera pública. Elas sofreram - e continuam sofrendo - discriminações de vários tipos, opressóes e violências por parte de um modelo epistemológico androcentrado.

De acordo com Del Priore (2005) a história das mulheres foi fundada na constataçáo da negação e do esquecimento. Ganhou força somente a partir de 1970, pelo movimento feminista, concomitantemente ao florescimento da Antropologia e da história das mentalidades (VAINFAS, 1997), principalmente da memória popular. A autora observa que dois polos foram fundamentais nessa efervescência intelectual: a necessidade de fazer despontar as mulheres no meio de uma história pouco preocupada com as diferenças sexuais e, numa segunda instância, demonstrar a exploração e a dominação desse universo feminino, que as subjugam.

Outra razão para as dificuldades em fazer uma história das mulheres era a constataçáo do silêncio a que se era confrontado ao fazer uma interpretação das fontes. Náo havia pistas nem marcas. Elas não nos deixaram suas próprias impressōes no material histórico levando os críticos dos anos 80 a outra pergunta: o que é a história quando se é mulher e de que maneira participa, ou não, enquanto mulher do processo histórico? (PRIORE, 2005, p. 223-224).

Para Scott (1992), o termo gênero - utilizado para teorizar a questão da diferença sexual - refere-se aos contextos social e cultural, podendo desdobrar-se em diferentes sistemas articulados com categorias, a exemplo de raça e classe. Dessa maneira, a diferença relativa ao gênero - mulher/homem - se subdivide em outras diferenças em termos de classe social, condição financeira, raça, sexualidade, lugares de pertencimento, entre outros, que constituem essa diferenciação inicial. Assim, de uma postura inicial que postulava uma identidade única e homogeneizadora para 
as mulheres, passou-se à outra, que privilegiou a certeza da existência de múltiplas identidades. Ou seja, "[...] há diferenças na diferença! [...]", como adverte Scott (1992, p. 88). Essa constatação trouxe à tona um debate que torna possível articular o gênero como categoria de análise, o que se constitui na opção metodológica adotada neste texto, não perdendo de vista que ela precisa ser articula com outros condicionantes sociais, tais como raça, classe social e lugar de pertencimento.

$\mathrm{O}$ conceito de gênero, articulado a outras relaçóes sociais, evidencia diversos sistemas de poder e de dominação, trazendo a dimensão política para a análise (SCOTT, 1991). Esse conceito pode ser uma categoria útil de análise históricoliterária, na medida em que assegura operacionalmente um maior detalhamento de processos sociais pouco conhecidos. Assim, na visão de Scott (1992), a História das mulheres deve ser um campo inevitavelmente político, como política deve ser a postura do intelectual, voltado à pesquisa necessária, como propóe Abdala Júnior (2002) ao defender o mundo plural das representaçôes humanas. Vozes que se unem na direção do preenchimento de vazios deixados pela formação escolar com base em uma história e literatura únicas, nos termos da escritora nigeriana Chimamanda Adichie (2009).

Nos Parâmetros Curriculares Nacionais (PCN), publicados pelo Ministério da Educação (MEC), em 1997, as relações de gênero foram incluídas como parte do tema transversal Orientação sexual, um indício claro de mais uma conquista dos movimentos feministas. Porém, como adverte Luciana Gandelman:

A categoria de gênero aparece esvaziada de seus aspectos políticos e históricos, dizendo respeito, ao contrário, unicamente ao âmbito da família e das relaçóes interpessoais. A categoria criada pelos $\mathrm{PCN}$ não inclui noçôes de conflito. Não faz menção aos sujeitos históricos e às relações sociais que estáo constantemente construindo as representaçóes e relaçôes de gênero. Como consequência dessa postura, não associa as relaçóes de gênero às relaçóes de poder em geral que constituem a sociedade. Esta definição acaba por tratar as representaçóes como prontas e acabadas, e não como fruto de embates constantes. (GANDELMAN, 2003, p. 213).

Quanto ao livro didático, Choppin observa a dificuldade de se definir o objeto, devido a diversos fatores, que vão desde a diversidade do vocabulário à instabilidade dos usos lexicais, bem como identifica que o livro didático assume variadas funçóes no chão da escola: função referencial, curricular ou programática; função instrumental; função ideológica e cultural e, por último, função documental (CHOPPIN, 2004). 
De acordo com Bittencourt (2008), o livro didático é antes de tudo uma mercadoria, um produto sujeito às técnicas de fabricação e comercializaçáo inerentes à lógica do mercado, sofrendo interferências de vários indivíduos. É um instrumento pedagógico inscrito em uma longa tradição, produzindo uma série de técnicas de aprendizagem; ele apresenta não apenas o conteúdo da disciplina, mas como esse conteúdo deve ser ensinado, tornando-se importante veículo de um sistema de valores, de uma ideologia, de uma cultura, permanecendo como o principal instrumento de trabalho de professores e alunos.

Alvo de polêmicas e controvérsias, essa fonte às vezes se torna a única a ser utilizada pelo professor em sala de aula e, não sendo muito pessimista, torna-se o único livro manuseado durante uma vida inteira por parte de muitos brasileiros. Nesse rumo, a leitura dessa fonte esclarece o que era ensinado e como o aluno poderia aprender o que era ensinado. Em suas páginas, podemos identificar quais as imagens de mundo e de sociedade a escola deseja forjar no imaginário dos alunos. Ao se transformar num poderoso - e, muitas vezes, o único auxiliar de ensino para o aluno e o professor, "[...] este tipo de documento tem se tornado muito significativo para a pesquisa tanto dos conteúdos ensinados como dos métodos usados na sala de aula" (PIRES, 1994, p. 111).

Em linhas gerais, livro didático é todo livro pensado e elaborado para um fim específico de ensinar alguma coisa, transmitir algum conhecimento independente do conteúdo. Lajolo assim define o livro didático:

É o livro que vai ser utilizado em aulas e em curso que provavelmente foi escrito, editado, comprado, tendo em vista essa utilização escolar e sistemática, assim para ser considerado didático, o livro precisa ser utilizado de forma sistemática de ensino/aprendizagem de um determinado objeto do conhecimento humano. (LAJOLO, 1996, p. 4).

Segundo Gabriel, o livro didático é espaço de hibridização e didatização cultural. Dialogando com os estudos culturais e com as contribuiçóes das teorias curriculares críticas e pós-críticas, essa autora privilegia evidenciar a dimensão política do cultural (GABRIEL, 2009). Os valores expressos nos livros são hibridizados, ou seja, eles recontextualizam, com base na ótica de seus autores e editores, orientaçóes oficiais, discursos escolares e acadêmicos, bem como dos contextos internacionais e o das produçóes pedagógicas que penetram no mercado editorial. Nessa recontextualização, esses discursos são hibridizados, visando finalidades distintas (GABRIEL, 2009). 


\section{Descolonialismo: um referencial teórico para estudos de gênero}

Ao estudar o lugar ocupado pela mulher nas narrativas histórica e literária, presentes no PNLD para o Ensino Médio, referente ao ano 2015, este estudo busca aproximação com alguns autores dos Estudos Culturais e Pós-Coloniais, tais como Stuart Hall e Ramon Grosfoguel (2008), bem como Edward Said (2011) e Homi Bhabha (1996; 2010), entre outros. A escolha desses teóricos tem como intento localizar este trabalho dentro de um viés de abordagens interdisciplinares e interculturais, além de considerar cultura e identidade - ampliado para a questão de gênero - como categorias híbridas e plurais, denunciando variadas formas de imperialismos, racismos e o caráter excludente das construçóes identitárias, como é o caso dos livros didáticos que serão analisados.

Outro aspecto relevante é a consciência da (des)colonização do pensamento em países que sofreram tal processo, como é o caso do Brasil. Torna-se imperativa uma relativização da matriz teórica eurocentrada, que obedece à lógica da colonialidade, nos termos de Quijano (2005), ou seja, uma característica que reprime os modos de produçáo de conhecimento, saberes, símbolos e imaginário do colonizado, operando-se uma naturalização do invasor europeu e a subalternização do não europeu, somadas à própria negação e o esquecimento de seus processos históricos.

Tal escolha teve como principal intuito fundamentar o processo de desconstrução da abordagem das fontes analisadas, que ainda refletem o ponto de vista do colonizador branco, eurocentrado, androcêntrico, cristáo e racista. No livro A falsa medida do homem, do biólogo Stephen Jay Gould (1999), observa-se que os cientistas do século XIX comparavam o nível de mentalidade dos negros, indígenas e mulheres ao de crianças, o que evidenciava sua incapacidade de autodeterminação e a necessidade de tutela. Atributos femininos eram utilizados pelos homens de ciência para desqualificar os povos tidos como inferiores biológica e culturalmente, como os africanos. Nesse modelo de saber e poder, a participação do sujeito feminino, na qualidade de agente histórico e literário, na maioria das vezes sofreu processos de interdição.

A fim de aflorar o conceito de gênero - como categoria de análise dos livros didáticos - optou-se inicialmente pela concepção teórica pós-colonial, cujo termo, de acordo com Hall, não se restringe apenas à descrição de determinadas sociedades ou épocas:

Ele relê a colonização como parte de um processo global essencialmente transnacional e transcultural - e produz uma reescrita descentrada, diaspórica ou global das grandes 
narrativas imperiais do passado, centrada na nação. Tratase de como as relaçóes transversais e laterais que Gilroy denomina diaspóricas complementam e ao mesmo tempo deslocam as noçóes de centro e periferia, e de como o global e o local reorganizam e moldam um ao outro. (HALL, 2013, p. 119).

O conceito, apesar de se encontrar em processo de construção epistemológica, náo se limita geográfica nem temporalmente, podendo constituir uma interessante postura político-epistemológica para apreender o tema estudado, na medida em que sinaliza uma "[...] proliferação de histórias e temporalidades, a intrusão da diferença e da especificidade nas grandes narrativas generalizadoras do pósiluminismo eurocên trico" (HALL, 2013, p. 121).

As atuais discussóes, no atinente ao currículo por parte do MEC acerca de uma Base Nacional Curricular Comum (BNCC), por exemplo, revelam indícios da posiçáo de uma inteligentsia manifestadamente colonializada, na medida em que se sentiu ameaçada pela invasáo bárbara contemporânea ao currículo eurocentrado, que, historicamente, tem prescrito o conteúdo escolar. A proposta não pretende eliminar conteúdo consagrado pela longa tradição historiográfica e literária europeia ocidental, apenas dessacralizá-la e descentralizá-la. Os questionamentos devem abarcar, além das relaçóes de poder e de gênero, as formas de conhecimento que entronizaram "[...] o sujeito imperial europeu na sua posição atual de privilégio" (SILVA, 2013, p. 127). É preciso ter em mente as relaçóes assimétricas de poder, sejam elas entre as naçóes que trazem rótulos de desenvolvidas e subdesenvolvidas, ou as que foram divididas de forma hierarquizada em norte e sul, e até mesmo colonialismos internos em uma mesma nação.

As diferenças e hierarquizaçóes presentes nessas tramas e narrativas didáticas não podem ser entendidas fora dos processos linguísticos de significação, elas são produzidas discursivamente. Além disso, segundo Silva:

[...] a diferença é sempre uma relação: não se pode ser 'diferente' de forma absoluta; é-se diferente relativamente a alguma outra coisa, considerada precisamente como 'náo diferente'. Mas essa 'outra coisa' não é nenhum referencial absoluto, que exista fora do processo discursivo de significação: essa 'outra coisa', o 'não diferente', também só faz sentido, só existe, na 'relação de diferença' que a opóe ao 'diferente'. $\mathrm{Na}$ medida em que é uma relação social, o processo social, o processo de significação que produz a 
'diferença' se dá em conexão com relaçôes de poder. São as relaçōes de poder que fazem com que a 'diferença' seja avaliada negativamente relativamente ao 'não diferente'. Inversamente, se há sinal, se um dos termos da diferença é avaliado positivamente (o 'não diferente') e o outro, negativamente (o 'diferente'), é porque há poder. (SILVA, 2013, p. 87, grifos do autor).

O currículo, assim como o livro didático, sendo espaços de poder, podem consagrar uma identidade em detrimento de outras. Dessa forma, precisam ser constantemente reavaliados e ressignificados de acordo com as demandas sociais. Um currículo múltiplo e pluriversal pode atender melhor as expectativas e necessidades dos tempos atuais, assim como uma abordagem que descolonialize o saber e reinvente o poder, tal qual a proposta de Boaventura de Souza Santos (2010). Para o sociólogo português, o fim do colonialismo político europeu, epistemicídio, em seus termos, náo significou o fim do colonialismo das mentalidades e das subjetividades na cultura e na epistemologia; muito pelo contrário, continua a se reproduzir de modo endógeno (SANTOS, 2010). De acordo com Rago (1997), a própria ideia de colonização traz dentro de si sentidos de posse do feminino. A metáfora do estupro, defloramento, penetraçáo, é recorrente para explicar o domínio sobre o território e as gentes da colônia. A metrópole seria o macho ativo; e a colônia, a fêmea passiva, a ser ocupada, colonizada e dominada.

O caso é que a situação de colonialidade ainda persiste em pleno século XXI. E, nesse aspecto, o aparato teórico pós-colonial se torna muito bemvindo, na medida em que denuncia contrapontos, subalternidades, não lugares, entrecampos, violências epistemológicas, silêncios, estereótipos, racializaçóes e hierarquizações.

Devemos, pois, ler os grandes textos canônicos, e talvez também todo arquivo da cultura europeia e americana prémoderna, esforçando-nos por extrair, entender, enfatizar e dar voz ao que está calado, ou marginalmente presente ou ideologicamente representado em tais obras. (SAID, 2011, p. 123).

Com uma opçáo teórica como essa, pode-se, nos termos de Foucault (2005), ressaltar os saberes sujeitados, ou seja, todo um conjunto de conhecimentos que foram silenciados pelas circunstâncias históricas estabelecidas por densas relaçóes de poder e que foram desqualificados e deslegitimados em nome de um conhecimento verdadeiro (FOUCAULT, 2002). Tal qual Said postulou, 
assentado na proposta de uma leitura contrapontistica das grandes narrativas coloniais da literatura ocidental ${ }^{4}$, almeja-se, no presente trabalho, desvendar outras histórias e personagens eclipsadas nas narrativas analisadas, a exemplo do protagonismo das mulheres. Ao sobrepor os diferentes territórios e ao entrelaçar histórias, para além da narrativa, pode-se flagrar micro imperialismos culturais, no intuito de denunciar suas perspectivas ideológicas dominantes nos livros didáticos, por exemplo.

Há diversos tipos de pós-colonialismos, assim como autores/teóricos póscoloniais. O conceito, como observado em outras passagens, não se limita espacial nem temporalmente, de acordo com Hall. Portanto, não se refere exclusivamente ao processo de descolonização afro-asiático de meados do século passado. Dessa forma, podemos estender essa condição para as sociedades que surgiram após o processo de descolonização durante o século XIX, cujas colonizações remontam ao século XVI, inaugurando o período histórico conhecido como modernidade.

Uma das formas de romper com a essencialidade das identidades pode se localizar nos deslocamentos, seja por obrigação, seja por opçáo, ocasional ou constantemente. As diásporas, como a dos negros; ou deslocamentos de pessoas das antigas colônias para as antigas metrópoles; as constantes ondas migratórias às fronteiras da Europa; ou mesmo uma simples viagem, que proporciona uma situação de sentir-se estrangeiro, isso tudo pode ser vivenciado, ainda que temporariamente, como o outro. Nesse sentido, experimentam-se as "[...] delícias e as inseguranças da instabilidade e a precariedade da identidade" (SILVA, 2009, p. 87-88). Para Gilroy, a diáspora é uma ideia valiosa porque aponta para um sentido mais refinado e mais maleável de cultura do que as noçóes características de enraizamento. Ela oferece uma alternativa imediata à disciplina severa do parentesco primordial e do pertencimento enraizado. Eis como ela funciona:

Uma alternativa à metafísica da raça, da nação e da cultura delimitada e codificada no corpo, a diáspora é um conceito que problematiza a mecânica cultural e histórica do pertencimento. Ela perturba o poder fundamental do território na definição da identidade ao quebrar a sequência simples de elos explanatórios entre lugar, localização e consciência. (GILROY, 2007, p. 151).

4 De acordo com Edward Said, a Literatura comparada, uma espécie de antídoto ao nacionalismo redutor e ao dogma acrítico, surgiu, ironicamente, no auge do imperialismo europeu e está inegavelmente ligado a ele (SAID, 2011). 
O processo de hibridação, decorrente desses deslocamentos, em geral conflituosos, oportuniza a formação de outras identidades, não sendo necessariamente determinada pela identidade hegemônica, pois, apesar de conservar traços dela, introduz a diferença que constitui possibilidades para seu questionamento (SILVA, 2009).

Se a crítica pós-colonial foi importante o avanço epistemológico na abordagem do processo pós-emancipatório da África e Ásia de meados do século $\mathrm{XX}$, a crítica decolonial torna-se mais frutífera para nosso lugar, na medida em que carreia para o debate as especificidades do continente americano, não desconsiderando o processo de colonização do século XVI. Dessa forma, podese pensar que o decolonial seria o pós-colonial para os americanos, excetuando os estadunidenses? Pensamos que o fator mais relevante dessa abordagem se localiza no seu caráter intrinsecamente endógeno, ou seja, o desenvolvimento de uma episteme a partir da latino-americanidade.

Para os estudos de gênero, adotar uma postura teórica pós-colonial/ decolonial é atentar-se para a necessidade de náo apenas incluir as mulheres nos espaços que sempre foram interditados a elas. Nos dizeres de Silva (2009), não se trata de uma questáo de acesso, mas de perspectiva. Como bem assegurou Scott (1992), as mulheres náo podem simplesmente ser adicionadas nas narrativas objetivas, neutras e universais, sem uma ruptura dos padróes, termos e suposições, pois essa concepção de história estabelecia em sua própria definição a exclusão das mulheres. Se a definição do homem permanece na subordinação da mulher, então uma modificação substancial na condição da mulher requer uma modificação em nossa compreensão do homem (SCOTT, 1992).

De acordo com Soihet e Pedro (2007, p. 285), esses estudos

[...] apoiam-se em outras disciplinas - tais como a literatura, a linguística, a psicanálise e, principalmente, a antropologia, com o intuito de desvendar as diversas dimensões do objeto. Assim, a interdisciplinaridade assume importância nos estudos sobre o feminino.

Segundo Miskolci (2007), amparado nos estudos de Michel Foucault, a sexualidade como um dispositivo histórico do poder se desenvolveu desde fins do século XVIII nas sociedades ocidentais modernas e se baseou na inserçáo do sexo em sistemas de utilidade e regulação social, criando hierarquizaçóes e determinismos sociais.

Para Rago (1998), a emergência dos estudos sobre a história das mulheres e das relaçóes de gênero, em larga medida, permitiu o desmonte dessa naturalização 
da noção essencializada de mulher. No caso da área de História, implicou na importância da sexualização do discurso historiográfico. Nesse sentido, essa escrita feminina/feminista da história avançou a crítica "[...] questionando a figura do sujeito unitário, racional, masculino que se colocava como representante de toda a humanidade. As mulheres, portanto, não tinham história, absolutamente excluídas pela figura divina do Homem, que matara Deus para se colocar em seu lugar" (RAGO, 1998, p. 91).

É por essa perspectiva teórica que analisamos, na próxima seção, os guias didáticos do PNLD para as disciplinas de língua portuguesa e história.

\section{Análise dos Guias do PNLD - 2015 para o ensino médio à luz da questão de gênero}

Como dito em outras seções, o livro didático é o principal artefato cultural de difusão do conhecimento e da aprendizagem no sistema educacional brasileiro, constituindo importante fonte para uma história da disciplina por conter seu conteúdo explícito e apresentar os exercícios a serem realizados pelos professores e alunos na sala de aula. Particularmente, nos últimos anos, com a política do Programa PNLD, o livro didático também se revestiu de um papel no mercado com a venda de milhares de livros. Portanto, ele deixa de ter apenas sua função original para ter uma ferramenta econômica fundamental na indústria editorial brasileira.

Como Luca sustenta:

O PNLD pode ser encarado como o ápice de um processo que, de forma institucional, possibilita às empresas envolvidas na ediçáo desse tipo de material um mercado não apenas seguro e estável, mas em constante crescimento, num contexto em que a compra e venda de livros didáticos correspondem a mais de $60 \%$ do total das atividades. (LUCA, 2009, p. 171-172).

A autora verificou também que, no caso desses livros, há o acréscimo de um quarto elemento da tríade proposta por Antônio Candido (1997), em Formaçâo da Literatura Brasileira: escritor - obra - público. Com os livros didáticos, essa tríade se transforma em um quadrilátero com a presença do Estado, seu maior comprador (LUCA, 2009). O valor pago pelo governo federal ao ramo editorial 
a cada edição do PNLD supera os nove dígitos ${ }^{5}$. O PNLD faz parte de uma política pública priorizada pelo governo federal por meio do MEC e pelo Fundo Nacional do Desenvolvimento da Educação (FNDE), que normatizam escolhas, compras, lançamento de editais e avaliações dos Livros Didáticos (OLIVEIRA, 2013; BEZERRA; LUCA, 2006).

As fontes selecionadas para o presente texto se consubstanciam nos Editais do PNLD/2015 e nos Guias de avaliação endereçados aos professores e professoras de Português e História do ensino médio. A ideia é verificar se há uma indução, por parte dos agentes avaliadores, da presença do protagonismo feminino, bem como se há referências acerca das discussóes relativas a (trans)generidades presentes nas referidas coleçóes ${ }^{6}$.

De acordo com o Edital, no item 2.1.2, serão excluídas as obras didáticas nessas condiçóes:

Veicularem estereótipos e preconceitos de condição socioeconômica, regional, étnico-racial, de gênero, de orientação

5 No site do FNDE pode-se ter a dimensão do mercado em cifras. Os dados para o PNLD/2015 revelam que $\mathrm{R} \$ 898.947 .328,29$ foram investidos no ensino médio e $\mathrm{R} \$ 453.671 .005,72$ se destinaram ao ensino fundamental. Disponível em: <http://www.fnde.gov.br/programas/livro-didatico/livro-didatico-dadosestatisticos>. Acesso em: 7 out. 2016.

6 No Programa Nacional do Livro Didático para o Ensino Médio de 2015 houve a aprovação de 19 coleçōes de História e 10 de Português. São elas: Português: Contexto, Interlocução e Sentido (Maria Luiza Abaurre/ Maria Bernadete Abaurre/Marcela Pontara); Lingua Portuguesa (Roberta Hernandes/Vima Lia Martin); Lingua Portuguesa: Linguagem e Interaçaao (Carlos Emílio Faraco/Francisco Marto de Moura/José Hamilton Maruxo Junior); Novas Palavras (Emília Amaral/Mauro Ferreira/Ricardo Leite/Severino Antônio); Português: Lingua e Cultura (Carlos Alberto Faraco); Português Linguagens (Wiliam Roberto Cereja/ Thereza Magalhães); Português: Linguagens em Conexão (Graça Sette/Márcia Travalha/Rozário Starling); Vozes do Mundo: Literatura, Lingua e Produção de Texto (Lilia Santos Abreu-Tardelli/Lucas Sanches Oda/ Salete Toledo); Ser Protagonista Lingua Portuguesa (Rogério de Araújo Ramos); Viva Português (Elizabeth Marques Campos/Paula Cristina Marques/Cardoso M. Pinto/Silvia Letícia Andrade); Caminhos do Homem (Adhemar Marques/Flávio Berutti); Conexão História (Roberto Catelli Junior); História (José Geraldo Vinci de Moraes); Integralis - História (Divalte Garcia Figueira); História: Cultura e Sociedade (Sandro Vieira/Jean Moreno); História em Debate (Rosiane de Camargo/Renato Mocellin); História em Movimento (Gislane Seriacopi/Reinaldo Seriacopi); História Geral e do Brasil (Cláudio Vicentino/ Gianpaolo Dorigo); História Global: Brasil e Geral (Gilberto Cotrim); História para o Ensino Médio (Marcos Napolitano/Mariana Villaça); História, Sociedade e Cidadania (Alfredo Boulos Junior); História (Ronaldo Vainfas/Sheila de Castro Faria/Jorge Ferreira/Georgina dos Santos); Nova História Integrada (João Paulo Mesquita/Hidalgo Ferreira/Luiz Estevam de Oliveira Fernandes); Novo Olhar História (Marco César Pelegrini/Adriana Machado Dias/Keila Grinberg); Oficina de História (Flávio de Campos/Regina Claro); Por Dentro da História (Pedro Santiago/Maria Aparecida Pontes/Célia Cerqueira); Ser Protagonista História (Valéria Vaz); História - Das Cavernas ao Terceiro Milênio (Patrícia Ramos Braick/Myriam Becho Mota); Conexöes com a História (Alexandre Alves/Letícia Fagundes de Oliveira). Disponível em: <http:// www.fnde.gov.br/programas/livro-didatico/livro-didatico-dados-estatisticos>. Acesso em: 20 maio 2017. 
sexual, de idade ou de linguagem, assim como qualquer outra forma de discriminação ou de violação de direitos. (BRASIL, 2015, p. 40).

O Edital chama atenção apenas para a veiculação de estereótipos e preconceitos, mas silencia quanto ao protagonismo da mulher nas coleçóes. Com relação a componente Português, apenas duas delas foram mencionadas pelo Guia, atendendo a questóes relativas ao tema gênero, mesmo que de forma superficial e associadas a outras obrigatoriedades, tais como preconceito étnico, colonização e escravidáo, seguindo o caráter abrangente do Edital, à luz da citação anterior.

A coleção Lingua Portuguesa, de Roberta Hernandes e Vima Lia Martin, foi uma das que o Guia enfatizou para o fato de abordarem "[...] literatura feminina e indígena, além de discutir questóes relativas à colonização, escravidão, preconceito étnico e de gênero" (BRASIL, 2014b, p. 35). Dessa forma, seguindo as prescriçôes do Edital, as relaçôes de gênero são abordadas em conjunto com outras demandas sociais. A outra coleção, Lingua Portuguesa: Linguagem e Interação, segundo o Guia, estimula os alunos a identificar o preconceito de gênero em letras de música, programas de humor e propagandas (BRASIL, 2014b). Não há referências ao tema das (trans)generidades.

Nas outras oito coleçóes de Português aprovadas, o Guia destaca apenas algumas frases genéricas e isoladas na seção intitulada Construção da Cidadania, sem nenhuma referência à temática do protagonismo feminino, bem como acerca das relaçóes de gênero. Uma preocupação dos avaliadores foi alertar para a literatura africana (BRASIL, 2014b), diversidade e heterogeneidade cultural brasileira (BRASIL, 2014b), fruto da implantação da Lei 10.639/2003. Às vezes o Guia sinaliza apenas que determinada coleção aborda "[...] temáticas de interesse dos alunos do Ensino Médio" (BRASIL, 2014b, p. 77), ou mesmo violência, meio ambiente e preconceito, sem especificar tais termos de forma mais detalhada.

Com relação ao componente curricular História, que abraçou 19 coleçóes aprovadas, das 21 inscritas no Programa, o Guia, na seção Construção da Cidadania, observa que 11 delas abordaram a temática do protagonismo feminino, bem como das relaçóes de gênero. Uma delas mencionou de forma indireta o combate à homofobia. Outra coleçáo cuidou da liberdade de orientação sexual e religiosa e narrativas que inserem homossexuais, mulheres, indigenas e afrodescendentes. Outras coleçôes enfrentaram o tema da mulher positivada e como agente histórico. Em uma delas, a mulher aparece, mas a ênfase recai sobre aspectos da maternidade. 
Promovem-se estratégias para a convivência cidadã (...) combatendo o preconceito e discriminaçáo de caráter étnico-racial, social e de gênero, e incentivando o respeito pela diversidade. Principalmente nas seçóes, há referências sobre a história das mulheres. (BRASIL, 2014a, p. 24).

$\mathrm{Na}$ coleção acima, intitulada Caminhos do homem, dos autores Adhemar Marques e Flávio Berutti, o Guia evidencia referências esparsas sobre a história das mulheres, e a temática de gênero disputa espaço com materiais que dizem do âmbito étnico-racial e social.

Em Conexão história, de Roberto Catelli Junior, o Guia observa que a obra "[...] apresenta questóes para a crítica do racismo e do preconceito étnico, fomentando uma educação voltada à promoção dos Direitos Humanos que reforça a visibilidade de mulheres, povos indígenas e afrodescendentes" (BRASIL, 2014a, p. 29).

Sobre essa coleçáo, o Guia ainda aponta que, a fim de promover a cidadania, destacam-se imagens de mulheres em vários contextos históricos e sociais, bem como temas relacionados com movimentos e problemas sociais, questóes ambientais, relações de gênero e de luta pela terra (BRASIL, 2014a).

A coleção História: cultura e sociedade, de acordo com o Guia, destaca-se pela abordagem de questóes contemporâneas, tais como a educação para as relaçóes étnico-raciais, combate ao preconceito, à discriminação racial e à violência correlata. De igual parte, pontua questóes de gênero com foco dirigido à mulher, privilegiado o mundo do trabalho. $\mathrm{O}$ Guia observa ainda que a coleção incentiva o respeito à diversidade e à alteridade, além de versar de forma indireta, sobre o combate à homofobia (BRASIL, 2014a).

A Coleçáo História em movimento, náo bastasse apresentar a imagem da mulher como sujeito histórico, ainda vinculado a um aspecto da maternidade (ou da ausência dela), centrado no trabalho infantil, aponta reflexóes acerca da liberdade de orientação sexual e religiosa. Em adendo, a coleção citada se torna uma das únicas a abordar narrativas que inserem homossexuais na condição de sujeitos históricos, ressalvado que opção sexual e identidade de gênero são aspectos totalmente distintos (BRASIL, 2014a).

Em a História para o ensino médio (BRASIL, 2014a), de Marcos Napolitano e Mariana Villaça, há o reconhecimento, por parte dos avaliadores, de que a participação das mulheres foi contemplada de forma secundária nas narrativas, restritas a pequenas seçóes e boxes (fora da narrativa principal). A despeito disso, a coleção foi aprovada.

Já em História, sociedade e cidadania, de Alfredo Boulos Júnior, a condição de sujeito histórico da figura feminina, com atenção em momentos emblemáticos 
de ruptura e mudança, ainda se vincula à esfera do privado, distinguindo-se por seu papel na maternidade, quando afirma: "Destacam-se as imagens em que a criança está sendo cuidada" (BRASIL, 2014a, p. 78 e 81). Assim, de acordo com as reflexões de Gandelman (2003), estampadas algumas páginas atrás, a categoria de gênero emerge nessa coleção, esvaziada de seus aspectos políticos e históricos, dizendo respeito, isso sim, unicamente ao âmbito da família e das relaçóes interpessoais.

Malgrado a valorização do papel da mulher, na coleção História, de Ronaldo Vainfas et al. (BRASIL, 2014a), o Guia não explicita a forma nem em que setores ocorreu tal valorização, muito menos qual seria esse papel.

$\mathrm{Na}$ coleção Nova história integrada, de João Paulo Mesquita e outros, novamente a mulher, valorizada em textos e imagens, aparece fora da narrativa principal, ou seja, nas seçóes "[...] falando nisso [...]" e "[...] estudos de caso [...]" (BRASIL, 2014a, p. 92).

A coleção escrita por Flávio de Campos e Regina Claro, Oficina da história, foi mais uma das aprovadas com avaliação ruim por parte do Guia, ao reconhecer o caráter pontual das questôes concernentes ao gênero (BRASIL, 2014a).

Em Por dentro da História, de Pedro Santiago et al., a menção à mulher se mescla com diversos outros grupos, alguns deles abordados nas escolas por força da lei, a exemplo da obrigatoriedade de ensinar história e cultura africana, afro-brasileira e indígena para os alunos/alunas do ensino fundamental e médio (BRASIL, 2014a).

$\mathrm{Na}$ coleção História: das cavernas ao terceiro milênio, novamente o papel da mulher é realçado principalmente por meio de boxes e textos complementares (BRASIL, 2014a). Tal situação pode se tornar problemática, na medida em que geralmente fica a cargo do professor/professora, que, normalmente, pode deixar como mera atividade extraclasse, perdendo a chance de promover discussóes interessantes no que toca à formação da cidadania na sala de aula.

Diante da análise das fontes, pôde-se aferir que o Guia do PNLD/2015 atribuiu um peso maior às questóes de gênero na componente História. Outro ponto importante é que a discussão relativa ao tema ainda persiste no dualismo homem/mulher. Como consequência disso, apenas duas coleções, em meio às analisadas, abordaram temas como homofobia, liberdade de orientação sexual e inserção de homossexuais na qualidade de sujeitos históricos nas narrativas. Constatou-se também que há uma preocupação muito maior por parte do Guia com literatura africana (no caso do Guia de Português) e com questóes étnicoraciais motivadas pelas leis de 2003 e 2008 (no caso do Guia de História). 


\section{Reflexões finais}

Esse texto teve seu nascedouro em nossas inquietaçóes como pesquisadores preocupados com a tríade gênero, livro didático e educação. O estímulo em refletir sobre esse assuntou se tornou fundamental diante das diversas manifestações políticas de grupos conservadores que insistem em invisibilizar as questóes em torno de gênero, apesar do número bastante exacerbado de assassinatos de mulheres e de pessoas trans.

Neste artigo, no entanto, buscamos compreender como os guias dos livros didáticos de língua portuguesa e de história apresentam a questão de gênero. Da leitura das obras, a categoria gênero surge, tanto nos PCN, no Edital e no Guia do PNLD, desvinculada de aspectos políticos e das relaçôes assimétricas de poder constituintes da complexidade social. Está ausente o conflito, bem assim as lutas de representaçóes historicamente desiguais e hierarquizadas, na medida em que postas de forma pronta e acabada. Particularmente, neste momento histórico brasileiro, essas açôes podem ter um efeito minimizador de qualquer forma de resistência ao modus operandi. O silenciamento acaba fomentando apenas as diferentes formas de violência física e simbólica.

Para finalizar, não há menção alguma por parte dos guias de Português e de História à questão da identidade de gênero, muito menos acerca de transgeneridades. Dito isso, os educadores não conseguem mais se furtar a abordar tais questóes em suas salas de aula. Trata-se de demanda social urgente nos dias atuais. Mesmo querendo ignorar, ela se faz presente no cotidiano do profissional da educação. Dessa forma, temos um longo caminho para ser trilhado no que concerne a essas questóes, pois estão diretamente imbricados com a necessidade humana de sobrevivência. Devemos nos perguntar: Quais interesses estáo implicados? Quem ganha ou perde? Em pleno século XXI, desponta um número crescente de atrocidades, das mais variadas formas, contra diferentes grupos sociais. Até que ponto nosso silenciamento pode estimular essas manifestaçôes de violência?

\section{Referências}

ABDALA JÚNIOR, Benjamin. Fronteiras múltiplas, identidades plurais: um ensaio sobre mestiçagem e hibridismo cultural. São Paulo: Editora SENAC São Paulo, 2002.

ADICHIE, Chimamanda. Os perigos de uma história única. Palestra na Universidade de Harvard, jul. 2009. Disponível em: <http://www. Ted.com/ talks/Lang/eng/chimamanda_adichie_the_danger_of_asingle_history.htm $>$. Acesso em: 1 abr. 2010. 
BHABHA, Homi K. O local da cultura. Belo Horizonte: Ed. UFMG, 2010.

BHABHA, Homi K. O terceiro espaço. Entrevista concedida a Jonathan Rutherford. Revista do Patrimônio Histórico e Artístico Nacional. Rio de Janeiro, n. 24, p. 35-41, 1996.

BEZERRA, Holien Gonçalves; LUCA, Tânia Regina de. Em busca da qualidade: PNLD de História - 1996-2004. In: SPOSITO, Maria Encarnação Beltrão (Org.). Livros Didáticos de História e Geografia: avaliação e pesquisa. São Paulo: Cultura Acadêmica, 2006. p. 27-53.

BITTENCOURT, Circe Maria Fernandes. Livros didáticos entre textos e imagens. In: BITTENCOURT, Circe Maria Fernandes. O saber histórico na sala de aula. São Paulo: Contexto, 2008. p. 69-90.

BOSI, Alfredo. Ideologia e contraideologia: temas e variaçóes. São Paulo: Companhia das Letras, 2010.

BRASIL, Ministério da Educação. Guia de livros didáticos: PNLD 2015: História: ensino médio. Brasília, DF: MEC, Secretaria de Educação Básica, 2014a. Disponível em: <http:/www.fnde.gov.br/programas/programas-do-livro/ livro-didatico/guia-do-livro-didatico/item/5940-guia-pnld-2015>. Acesso em: 20 out. 2017.

BRASIL, Ministério da Educação. Guia de livros didáticos: PNLD 2015: Português: ensino médio. Brasília, DF: MEC, Secretaria de Educação Básica, 2014b. Disponível em: <http://www.fnde.gov.br/programas/programas-dolivro/livro-didatico/guia-do-livro-didatico/item/5940-guia-pnld-2015>. Acesso em: 20 out. 2017.

BRASIL, Ministério da Educação. Edital de convocaçáo para o processo de inscriçáo e avaliaçáo de obras didáticas para o Programa Nacional do Livro didático - PNLD 2015, Brasília, DF. Disponível em: <http://www.fnde.gov. br/programas/programas-do-livro/consultas/editais-programas-livro/item/4032pnld-2015>. Acesso em: 10 jan. 2018.

BRASIL, Ministério da Educação. Obras aprovadas - PNLD 2015. Diário Oficial da Uniáo, Brasília, DF, seção 1, n. 146, de 01/08/2014. Disponível em: <https://e-dou.com.br/2014/08/diario-oficial-da-uniao-secao-1-01-08-2014>. Acesso em: 10 jan. 2018.

CANDIDO, Antônio. Formaçáo da Literatura brasileira. (1836-1880). Belo Horizonte-Rio de Janeiro: Itatiaia, 1997. 
CHOPPIN, Alain. História dos livros e das edições didáticas: sobre o estado da arte. Educaçáo e pesquisa, São Paulo, v. 30, n. 3, p. 549-566, set./dez. 2004.

FOUCAULT, Michel. A ordem do discurso. Aula inaugural no Collège de France, pronunciada em 2 de dezembro de 1970. São Paulo: Ediçóes Loyola, 2002.

FOUCAULT, Michel. Em defesa da sociedade. Curso no Collège de France (1975-1976). São Paulo: Martins Fontes, 2005.

GABRIEL, Carmen Teresa. "Exercícios com documentos" nos livros didáticos de história: negociando sentidos da história ensinada na educação básica. In: ROCHA, Helenice Aparecida Bastos et al. (Org.). A História na escola: autores, livros e leituras. Rio de Janeiro: Ed. FGV, 2009. p. 245-249.

GANDELMAN, Luciana M. Gênero e ensino: parâmetros curriculares, fundacionalismo biológico e teorias feministas. In: ABREU, Martha; SOIHET, Rachel (Org.). Ensino de História: conceitos, temáticas e metodologia. Rio de Janeiro: Casa da Palavra/FAPERJ, 2003. p. 209-220.

GILROY, Paul. Entre campos: nações, culturas e o fascínio da raça. São Paulo: Annablume, 2007.

GOULD, Stephen Jay. A falsa medida do homem. São Paulo: Martins Fontes, 1999.

GROSFOGUEL, Ramón. Para descolonizar os estudos de economia política e os estudos pós-coloniais: Transmodernidade, pensamento de fronteira e colonialidade global. Revista Crítica de Ciências Sociais, Coimbra, n. 80, p. 115-147, mar. 2008.

HALL, Stuart. Quando foi o pós-colonial? Pensando no limite. In: Da diáspora: identidades e mediações culturais. Belo Horizonte: Ed. UFMG, 2013. p. 110-140.

LAJOLO, Marisa. Livro Didático: um (quase) manual de usuário. Em Aberto, Brasília, DF, ano 16, n. 69, p. 3-9, jan./mar.1996.

LUCA, Tânia Regina de. Livro didático e Estado: explorando possibilidades interpretativas. In: ROCHA, Helenice Aparecida Bastos et al. (Org.). A História na escola: autores, livros e leituras. Rio de Janeiro: Ed. FGV, 2009. p. 151-172.

MARTINS, Estevão Rezende. Jörn Rüsen e o ensino de história. Curitiba: EdUFPR, 2011. 
MISKOLCI, Richard. A Teoria Queer e a questão das diferenças: por uma analítica da normalização. In: CONGRESSO DE LEITURA DO BRASIL, 16. 2007, Campinas. Anais... Campinas: ALB, 2007. Disponível em: <http://alb. com.br/arquivo-morto/edicoes_anteriores/anais16/prog_pdf/prog03_01.pd>. Acesso em: 10 jan. 2018.

OLIVEIRA, Margarida Maria Dias de. O Programa Nacional do Livro Didático (PNLD) e a construção do saber histórico escolar. In: GALZERANI, Maria Carolina Bovério et al. Paisagens da pesquisa contemporânea sobre o Livro Didático de História. Jundiaí: Paco Editorial; Campinas: Centro de Memória/ Unicamp, 2013. p. 357-372.

PIRES, Veríssimo Lopes. O ensino de História nas escolas primárias (19401950). Dissertação (Mestrado em Educação)- Faculdade de Educaçáo, Universidade de São Paulo, São Paulo, 1994.

PRIORE, Mary Del. Histórias das mulheres: as vozes do silêncio. In: FREITAS, Marcos César (Org.). Historiografia brasileira em perspectiva. São Paulo: Contexto. 2005. p. 217-235.

QUIJANO, Aníbal. Colonialidade do poder, eurocentrismo e América Latina. Buenos Aires: CLACSO - Consejo Latinoamericano de Ciencias Sociales, 2005.

RAGO, Margareth. Descobrindo historicamente o gênero. Cadernos Pagu, Campinas, v. 11, p. 89-98, 1998.

RAGO, Margareth. Sexualidade e identidade na historiografia brasileira. Resgate, Campinas, n. 7, p. 59-74, 1997.

RÜSEN, Jörn. Narratividade e objetividade nas ciências históricas. In: MARTINS, Estevão de Rezende et al. (Org.). Jörn Rüsen e o ensino de história. Curitiba: EdUFPR, 2011. p. 129-150.

RÜSEN, Jörn. O livro didático ideal. In: MARTINS, Estevão Rezende. Jörn Rüsen e o ensino de história. Curitiba: EdUFPR, 2011. p. 109-127.

SAID, Edward Wadie. Cultura e Imperialismo. São Paulo: Companhia das Letras, 2011.

SANTOS, Boaventura de Souza. Descolonizar El saber reinventar El poder. Montevidéu: Ediciones Trilce, 2010.

SCOTT, Joan W. Gênero: uma categoria útil de análise histórica. Recife: SOS Corpo, 1991. 
SCOTT, Joan W. História das mulheres. In: BURKE, Peter. A escrita da História: novas perspectivas. São Paulo: Ed. UNESP, 1992. p. 63-95.

SILVA, Tomaz Tadeu. Documentos de identidade: uma introdução às teorias do currículo. Belo Horizonte: Autêntica, 2013.

SILVA, Tomaz Tadeu. A produção social da identidade e da diferença. In: SILVA, Tomaz Tadeu. Identidade e diferença: a perspectiva dos estudos culturais. Petrópolis: Vozes, 2009. p. 73-102.

SOIHET, Rachel; PEDRO, Joana Maria. A emergência da pesquisa da História das mulheres e das relaçóes de gênero. Revista Brasileira de História, São Paulo, v. 27, n. 54, p. 281-300, 2007.

VAINFAS, Ronaldo. História das Mentalidades e História Cultural. In: CARDOSO, Ciro Flamarion; VAINFAS, Ronaldo. (Org.). Domínios da História: ensaios de teoria e metodologia. Rio de Janeiro: Elsevier, 1997. p. 127-162. 